\title{
Aggressiveness-related behavioural types in the pearly razorfish
}

\author{
Martina Martorell Barceló ${ }^{\text {Corresp., } 1}$, Júlia Mulet ${ }^{1,2}$, Javier Sanllehi ${ }^{1}$, Marco Signaroli ${ }^{1}$, Arancha Lana ${ }^{1}$, Margarida \\ Barcelo-Serra ${ }^{1}$, Eneko Aspillaga ${ }^{1}$, Josep Alós ${ }^{1}$ \\ ${ }^{1}$ Fish Ecology Group, Instituto Mediterráneo de Estudios Avanzados, IMEDEA (CSIC-UIB), Esporles, Spain \\ 2 Universitat de Barcelona, Barcelona, Spain \\ Corresponding Author: Martina Martorell Barceló \\ Email address: mmartorell@imedea.uib-csic.es
}

Behavioural types (i.e., personalities or temperament) are defined as among individual differences in behavioural traits that are consistent over time and ecological contexts. Behavioural types are widespread in nature and play a relevant role in many ecological and evolutionary processes. In this work, we studied for the first time the consistency of individual aggressiveness in the pearly razorfish, Xyrichtys novacula, using a mirror test: a classic method to define aggressive behavioural types. The experiments were carried out in semi-natural behavioural arenas and monitored through a novel Raspberry Pi-based recording system. The experimental set up allowed us to obtain repeated measures of individual aggressivity scores during four consecutive days. The decomposition of the phenotypic variance revealed a significant repeatability score $(R)$ of 0.57 [0.44-0.60], suggesting high predictability of individual behavioural variation and the existence of different behavioural types. Aggressive behavioural types emerged irrespective of body size, sex and the internal condition of the individual. Razorfishes are a ubiquitous group of fish species that occupy sedimentary habitats in most shallow waters of temperate and tropical seas. These species are known for forming strong social structures and playing a relevant role in ecosystem functioning. Therefore, our work provides novel insight into an individual behavioural component that may play a role in poorly known ecological and evolutionary processes occurring in this species. 


\section{Aggressiveness-related behavioural types in the pearly razorfish}

2 Martina Martorell-Barceló ${ }^{1 *}$, Júlia Mulet ${ }^{1,2}$ Javier Sanllehi $^{1}$, Marco Signaroli ${ }^{1}$, Arancha Lana ${ }^{1}$,

3 Margarida Barcelo-Serra ${ }^{1}$, Eneko Aspillaga ${ }^{1}$, Josep Alós ${ }^{1}$

4

5 'Fish Ecology Group, Instituto Mediterráneo de Estudios Avanzados, IMEDEA (CSIC-UIB),

6 Esporles, Illes Balears, Spain

$7 \quad$ 2Universitat de Barcelona, Barcelona, Spain.

8

$9 *$ Corresponding author

10 Martina Martorell Barceló ${ }^{1}$

11 Miquel Marquès 21, Esporles, Illes Balears, 07190, Spain

12 Email address: $\underline{\text { mmartorell@imedea.uib-csic.es }}$ 


\section{Abstract:}

14 Behavioural types (i.e., personalities or temperament) are defined as among individual 15 differences in behavioural traits that are consistent over time and ecological contexts. 16 Behavioural types are widespread in nature and play a relevant role in many ecological and 17 evolutionary processes. In this work, we studied for the first time the consistency of individual 18 aggressiveness in the pearly razorfish, Xyrichtys novacula, using a mirror test: a classic method 19 to define aggressive behavioural types. The experiments were carried out in semi-natural 20 behavioural arenas and monitored through a novel Raspberry Pi-based recording system. The 21 experimental set up allowed us to obtain repeated measures of individual aggressivity scores 22 during four consecutive days. The decomposition of the phenotypic variance revealed a 23 significant repeatability score $(R)$ of 0.57 [0.44 - 0.60], suggesting high predictability of 24 individual behavioural variation and the existence of different behavioural types. Aggressive 25 behavioural types emerged irrespective of body size, sex and the internal condition of the 26 individual. Razorfishes are a ubiquitous group of fish species that occupy sedimentary habitats in

27 most shallow waters of temperate and tropical seas. These species are known for forming strong 28 social structures and playing a relevant role in ecosystem functioning. Therefore, our work 29 provides novel insight into an individual behavioural component that may play a role in poorly 30 known ecological and evolutionary processes occurring in this species.

32 Key-words: Consistent individual differences, repeatability, mirror test, Xyrichtys novacula, 33 Mediterranean, animal personality. 


\section{INTRODUCTION}

36 Like humans, animals often behave in a way that distinguishes them from other members of their

37 species of the same sex and age (Gosling, 2001). When such behavioural differences are

38 consistent over time and ecological contexts, they can be referred to as behavioural types, also

39 known as personalities or temperament (Réale et al., 2007). Behavioural types often co-vary,

40 resulting in behavioural syndromes that are defined as correlations in two or more behavioural

41 traits (Sih, Bell \& Johnson, 2004). Behavioural types and syndromes are widespread across taxa

42 (Réale et al., 2007). In fishes, behavioural types are described along five major axes: boldness-

43 shyness, exploration-avoidance, aggressiveness, sociability and activity (reviewed in Réale et al.,

442007 and Conrad et al., 2011). The aggressiveness axis has received major attention due to its

45 relationship with a multitude of ecological processes such as growth or dominance in a social

46 hierarchy. However, the study of aggression per se is a complex trait to measure. Since

47 aggression is a way of socialising, individual characterisation of both behavioural axes can be

48 challenging. Strictly, aggressiveness has been defined as a hostile behaviour towards

49 conspecifics (McGhee \& Travis, 2010), and is usually related to agonistic interactions such as

50 territorial defence or competition for resources (Réale et al., 2007; Conrad et al., 2011). Under

51 controlled (laboratory) conditions, different tests have been used to measure aggressiveness, the

52 mirror test being the most common and accepted practice.

54 The mirror test consists of placing a mirror in front of the focal individual and measuring its

55 behavioural response (Francis, 1990; Budaev, Zworykin \& Mochek, 1999). Although the mirror

56 test has been widely used to estimate aggressive behaviour across animal taxa, considerable

57 controversy still exists about its validity in fish aggressiveness studies (Baenninger, 1968; 
58 Earley, Hsu \& Wolf, 2000; Balzarini et al. 2014). In this taxon, the mirror test has been used to

59 measure sociability (Cattelan et al. 2017); however, aggressive displays are a particular kind of

60 social interactions.

61

62

63

64

65

66

67

68

69

Another way to measure aggressiveness is by the opponent test, which consists of putting an intruder in the experimental arena and measuring the response of the focal individual. Some authors consider the opponent test as the only valid way to evaluate the aggressive response (Balzarini et al., 2014). In the opponent test, the reaction of the focal individual responds to the actions of the opponent in a manner that the focal intrinsic aggressiveness is not directly studied (Earley, Hsu \& Wolf, 2000). When the dominance status between focal and opponent is established, the opponent's position in the dominance hierarchy can be a source of potential problems. The dominance status will influence the response of the focal individual in an unknown way, making it difficult to obtain aggression levels that can be compared across trials and between individuals (Earley, Hsu \& Wolf, 2000). In contrast, the mirror test, by showing an "intruder" displaying exactly the same behaviours than the focal individual, provides with a constant reinforcement of aggressiveness and an unmodified image of a conspecific (Gallup, 1968; Rowland, 1999). Furthermore, studies in the past have shown that the individual aggressiveness estimated with the mirror test can predict the aggressiveness in competitive situations (Baenninger, 1968; Dore, Lefebvre \& Ducharme, 1978; Meliska, Meliska \& Peeke, 1980; Holtby, Swain \& Allan, 1993). These studies support the mirror test as a proper method to measure individual aggressiveness and provide empirical evidence showing that the results from this test are comparable to the behavioural responses in free-living conditions. However, this test needs to be adapted to the characteristics of the studied species. The most important aspects to 
81 consider are whether the focal individual responds to the stimulus (Rowland, 1999) and if it is

82 capable of self-recognition in front of a mirror (Balzarini et al., 2014). Most animal taxa,

83 including fishes, are suspected to treat their mirror reflection as a conspecific (Andrews, 1966;

84 Gallup, 1968; Kohda et al. 2019).

85

Aggressiveness-related behavioural types have important implications from the individual level

to the whole population dynamics (Sih, Bell \& Johnson, 2004). Aggressiveness is positively related to growth (Huntingford, 1998; Lahti et al., 2001) and metabolic rate (Cutts, Metcalfe \& Taylor, 2002), which depend on the internal state of the individual. The relative condition index (RCI) represents the fish internal state condition, and it is based on predicted body weight from a

91 length/weight relationship regardless of size. The RCI has been related to maturation and 92 reproduction of individuals (Morgan, 2004). Individual behavioural responses may modulate 93 internal energetic fluxes. For example, high energy requirements can imply high levels of 94 hunger, which can lead to aggressive displays to compete for food resources (Careau et al., 95 2008). Furthermore, testosterone regulates agonistic behaviours in males (Hirschenhauser et al., 96 2008), suggesting that aggressiveness and dominance in a social structure play an important role 97 in sexual selection and reproductive success (McGhee \& Travis, 2010). In zebrafish (Danio 98 rerio) and crayfish (Paranephrops planifrons), dominant individuals are the most aggressive 99 (Roy \& Bhat, 2018; May \& Mercier, 2007). This dominant position is sometimes related to size 100 or sex. For example, in green swordtail (Xiphophorus helleri), larger individuals are more 101 aggressive than smaller individuals (Wilson et al., 2011), while in the Midas cichlid 102 (Amphilophus citrinellus) males are more aggressive than females (Francis, 1990). Besides, 103 behavioural types are of most importance to understand the colonisation process by invasive 
104 species. Aggressive non-native fish are more likely to disperse from the original introductory

105 group and to better compete with native species, thereby improving the success of the invasion

106 (Rehage \& Sih, 2004). These individuals are also the most likely to leave their native population

107 to explore new environments and compete for new territories (Cote et al., 2010). Behavioural

108 types are also essential to understand the responses to intrusions among individuals of the same

109 population because the most aggressive ones will defend their territory more efficiently

110 (O’Connor et al., 2015). Therefore, aggressiveness is an important axis of behaviour significantly

111 affecting the ecology and evolution of many species (Taylor, 1990; Vøllestad \& Quinn, 2003).

112

113 In marine species, the study of aggressiveness has received less attention. Aggressiveness plays a

114 fundamental role in the mating behaviour of Two-spotted goby (Gobiusculus flavescens) (de

115 Jong et al., 2009). In Atlantic cod (Gadus morhua), there is a relationship between dominance

116 and fertilisation success, with dominance being established through agonistic interactions

117 between males, bigger individuals are the most aggressive, and therefore dominant over smaller

118 individuals (Hutchings, Bishop \& McGregor-Shaw, 1999). Furthermore, the existence of

119 aggressiveness-related behavioural types has been confirmed in European seabass

120 (Dicentrarchus labrax), (Millot et al., 2014).

121

122 Razorfishes are a ubiquitous group of fish species that inhabit most of the shallow sedimentary

123 habitats of tropical and temperate seas (Nemtzov \& Clark, 1994; Battaglia et al., 2010). Socially,

124 they are characterised by a complex haremic structure formed by a male and several females (4-6

125 females per male). The male defends his territory and the females that live in it from other males

126 (Marconato, And \& Marin, 1995; Cardinale, Colloca \& Ardizzone, 1998; Shen \& Clark, 2016). 
127 However, nothing is known on how behavioural types could be playing a role in the formation of

128 harems and other aspects of the social structure of this marine species. The pearly razorfish

129 (Xyrichtys novacula), is the only species of the genus Xyrichtys found in the Mediterranean Sea

130 (Candi et al., 2004). This species is a small-bodied wrasse that inhabits clear shallow waters with

131 sandy bottoms and sometimes areas covered by the seagrasses Cymodocea nodosa and Zostera

132 marina (Castriota et al., 2005; Battaglia et al., 2010). This species is distributed at depths

133 between 0 and $50 \mathrm{~m}$ (Fischer, Schneider \& Bauchot, 1987). It is a diurnal species and it buries

134 itself in the sand to rest and to avoid predators during the night-time (Alós, Cabanellas-Reboredo

135 \& Lowerre-Barbieri, 2012; Alós, Martorell-Barceló \& Campos-Candela, 2017). The pearly

136 razorfish has a carnivorous diet based on small benthic invertebrates, which differs depending on

137 the area but basically consists of molluses and crustaceans and occasionally of echinoderms and

138 polychaetes (Cardinale, Colloca \& Ardizzone, 1997; Castriota et al., 2005; Battaglia et al., 2010).

140 The pearly razorfish is a protogynous, monandric hermaphrodite. It has an appreciable sexual

141 dimorphism showing differences in head shape, length of pelvic fin and colouration patterns,

142 with females presenting a pearly spot on the abdomen (Cardinale, Colloca \& Ardizzone, 1998;

143 Candi et al., 2004). In the pearly razorfish, aggressiveness plays a fundamental role in the

144 establishment and maintenance of harems. Males are highly territorial and defend their harem

145 from other males in contiguous territories; male attacks against females have not been detected

146 (Shen \& Clark, 2016). The reproductive period of this species takes place during the summer

147 (July to September), and only dominant males participate in spawning (Marconato, And \&

148 Marin, 1995; Cardinale, Colloca \& Ardizzone, 1998). Despite the importance of this behavioural

149 trait, the individual repeatability for aggressiveness has never been explored in this species. 
150 Therefore, the pearly razorfish offers a unique opportunity to understand how an individual's

151 aggressiveness can determine its position in a complex social system.

152

153 The main objective of this study is to quantify for the first-time the aggressiveness in the pearly

154 razorfish and to determine the existence of behavioural types in this species. We determined the

155 repeatability of aggressiveness using metrics obtained under laboratory conditions applying a

156 standardised mirror test. We explored the effects of body size, sex, individual condition and the

157 effect of captivity and isolation in the expression of aggressiveness using generalised linear

158 mixed models and the decomposition of the phenotypic variance into between- and within-

159 individual components.

160

161 Our working hypotheses were i) individual aggressiveness is predictable - aggressiveness-related

162 behavioural types exist, ii) aggressiveness levels are higher in males and larger individuals (as a

163 response to an increased territorial defence), and iii) aggressiveness is negatively correlated with

164 the individual condition, as aggressive individuals spend more energy in antagonistic interactions

165 to protect their territory. Our work represents the first study on behavioural types in razorfishes,

166 providing the first step to understand the causes and consequences of individual behaviour in this

167 marine fish group.

168

\section{MATERIAL AND METHODS}

2.1. Origin of the experimental fish

171 From April $30^{\text {th }}$ to July $12^{\text {th }} 2019$, a total of 6 weekly sessions of experimental fishing were

172 carried out in shallow waters (10-15 m deep) of the Marine Protected Area in the Palma Bay, 
173 Mallorca (39 27'56" N 02 $43^{\prime} 37^{\prime \prime}$ E). Twelve fish were caught during each experimental fishing

174 session (this number was limited by the available experimental arenas, see below). Each fishing

175 session was carried out during the morning, from 10:00 to 14:00, using standardised hook-and-

176 line gear and live shrimp as bait (a classical capture method used by local recreational anglers).

177 Fish with deep-hooking (i.e., hooks reaching the internal/vital parts of the body) were not used

178 for this behavioural study to ensure that all individuals presented the least disturbance associated

179 with the capture method. Once 12 individuals were captured (after up to 1 hour of sampling), fish

180 were transported in an aerated 801 container with a constant oxygen flux from the capture site to

181 the Marine Research and Aquaculture Laboratory (LIMIA) in Andratx, Mallorca (39'32'39" N

$18202^{\circ} 22^{\prime} 42^{\prime \prime}$ E). At the LIMIA, fish were individually housed in the experimental behavioural

183 arenas for posterior behavioural testing (Figure 1). Neither mortalities nor stress (assessed

184 through visual inspection of the body) due to captivity and transport was observed.

185

186

\subsection{Characteristics of the behavioural arenas}

187 The present study constitutes the first attempt to maintain the pearly razorfish in social isolation.

188 The study of behavioural types in the pearly razorfish constitutes a new challenge because this

189 species requires specific attributes of the experimental arenas to simulate its natural environment.

190 In natural conditions, the pearly razorfish buries in the sand at night to avoid predators (Alós,

191 Cabanellas-Reboredo \& Lowerre-Barbieri, 2012; Alós, Martorell-Barceló \& Campos-Candela,

192 2017), and thus it is necessary to include the appropriate substrate in the experimental arenas to

193 provide this particular type of shelter. We developed several prototypes of behavioural arenas

194 before carrying out the experimental trials. The optimal behavioural arena was composed by an

195 aquarium of 1201 with closed UV-purified seawater re-circulation that allowed for complete 
196 control of light and temperature (see Figure 1). Each aquarium had its sump station where a

197 protein skimmer, bio-media for biological filtration and aeration maintained the optimal

198 conditions during the week (Figure 1). Each behavioural arena had the same quantity of sand (20

$199 \mathrm{~kg}$ ), which generated a $\sim 5 \mathrm{~cm}$ high accumulation of sand at the bottom with a precise 200 granulometry $(0.5-12 \mathrm{~mm})$ simulating the pearly razorfish habitat, allowing the fish to use the 201 sand as refuge.

202

203 The closed water system facilitated the control of environmental variables (such as temperature)

204 and facilitated the maintenance of the aquarium throughout the experimental period. The sand,

205 filters and the aquarium walls were cleaned and the water was changed before a new individual

206 was introduced in the behavioural arena. The temperature of each behavioural arena was

207 controlled by a water heater located in the sump of each aquarium, and it was programmed to

208 remain constant at $21^{\circ} \mathrm{C}$ (mean and s.d. of the water temperature for all experiments was $21.1 \pm$

$2091.8^{\circ} \mathrm{C}$ ). We used a light screen EHEIM powerLED + installed at the top of each behavioural

210 arena to reproduce the natural conditions of light/dark cycle, which was automatically controlled

211 with an EHEM LEDcontrol +. We reproduced a natural photoperiod of 12 hours of light and 12

212 hours of dark in which the sunrise was set at 07:00 and the sunset at 19:00. In this way, we

213 maximised the same environmental conditions to all individuals, an essential requirement to

214 study behavioural repeatability (Réale et al., 2007).

215

216 From all individuals captured, we only considered the ones from which we had at least two days

217 of experimental testing recordings. Due to some initial problems with the video generation and

218 storage of the novel tracking system (see below), we had to discard data from some individuals. 
219 For this study, we used the data from 49 wild pearly razorfish (37 females and 12 males) with an

220 average total length (TL) of $15.2 \pm 2.4 \mathrm{~cm}$ and total weight (TW) of $42.80 \pm 20.8 \mathrm{~g}$ (Figure 2).

221 Pearly razorfish were visually sexed as this species shows sexual dimorphism. Significant

222 differences in both TL and TW were observed between sexes as expected for a protogynous

223 hermaphrodite. Each individual was isolated in an experimental arena for one week (three days

224 for acclimation and four days for behavioural testing) and was assigned an individual identifier

225 number (ID). During this period, the individuals were fed $1 \mathrm{~g}$ of fresh shrimps per day. We were

226 able to observe that the behaviours recorded in the aquarium were the same as those recorded in

227 the sea, slow swimming, they buried themselves at night, or when scared, and they usually ate

228 every day, suggesting that we succeeded in providing suitable captive habitat for this species.

229

230

2.3. Video recording for data collection

231 During the week in captivity, all individuals were continuously monitored (video recorded in 2-

232 dimensions) using a camera set-up attached in front of each behavioural arena (Figure 1). The

camera set-up was based on a Raspberry Pi system equipped with an 8MP Raspberry Pi Camera

234 Module V2 with a Sony image sensor (Figure 1). The small camera allowed to record videos at

2351080 pixels with a framerate of 30 frames per second. A 128GB USB stick was connected to the

236 Raspberry Pi to store all the generated videos. A screen was attached to the Raspberry Pi where

237 the recordings could be played confirming the correct functioning of the system. This recording 238 system has proven useful for behavioural experiments (Jolles et al., 2019). Overall, we provide a

239 new experimental protocol that allows for the monitoring of individual razorfish under laboratory 240 conditions without disturbances (cameras were permanently mounted and recording) that can be 241 used for behavioural quantification in other species. 
243 During the experimental period, approximately $6900 \mathrm{~h}$ of recording were obtained. The

244 advantages of using the continuous recording for behavioural scoring are, i) raw data is

245 generated and adequately stored for reproducibility analysis, ii) fish are not unnecessarily

246 disturbed as the camera remains installed during the entire captive period, iii) it provides with the

247 opportunity to measure behaviour in real-time and, iv) it provides with the raw data for further 248 automatization of behavioural scoring through machine learning algorithms.

\subsection{Standardised aggressiveness test}

251

252

After the acclimation period (first three days), the individual behavioural assessments using the conventional mirror test started (Balzarini et al., 2014; Way et al., 2015). Each fish was subject to one test per day for four consecutive days. During testing, a mirror of the same size as the lateral side of the behavioural arena was externally attached to each aquarium for one hour during the daytime. Three different metrics were visually evaluated from the videos to estimate individual aggressiveness: i) the number of bites, defined as the number of times the individual bit the mirror, it was considered a bite when fish approached the mirror with their mouth open (Francis, 1990; Budaev, Zworykin \& Mochek, 1999; Bell \& Stamps, 2004; Bell, 2005; Scotti \& Foster, 2007; Snekser et al., 2009), ii) the number of rams, described as a fast approach with physical contact to the mirror but with the mouth closed (Balzarini et al., 2014) and, iii) the number of charges, described as a fast swim towards the mirror but without direct contact with it (Scotti \& Foster, 2007; Bell, Henderson \& Huntingford, 2010; Ryan White \& White, 2015). We were not able to obtain the four tests for all individuals due to problems with the storing of 
264 audio-visual material, but for 49 individuals a minimum of two measurements were obtained (see

265 sample size in Figure 2).

266

267

2.5. Data analysis

268 The degree of consistency in individual behaviour is usually quantified with the repeatability $(R)$

269 score (Nomakuchi, Park \& Bell, 2009). The $R$ score describes the proportion of phenotypic

270 variance that is explained by among-individual differences by decomposing between- and

271 within-individual variance thus defining behavioural types (Dingemanse \& Dochtermann, 2013).

272 The raw $R$ score was computed as the quotient between the between-individual variance $\left(\operatorname{Vind}_{0}\right.$,

273 the variance across random intercepts of individuals) and the within-individual variance $\left(\mathrm{Ve}_{0}\right.$,

274 residual variance, the variance associated with measurement error and phenotypic flexibility) for

275 a given behavioural score (Nakagawa \& Schielzeth, 2010; Dingemanse \& Dochtermann, 2013).

276 We used a Generalised Linear Mixed Model (GLMM) to decompose variances to estimate $R$ and

277 explore contextual effects using a Bayesian approach (Hadfield, 2010). To use a single

278 aggressiveness score in the model, we carried out a Principal Component Analysis (PCA) with

279 the three behavioural metrics (number of bites, number of rams and number of charges) at their

280 original scale (counts).We considered the values of the Principal Component 1 (PC1) as

281 aggressiveness score for fitting the GLMM (Figure 3).

282

283 Regarding the contextual variance and the structure of the fixed part of the GLMM, we 284 considered three variables: body size (related to sex), RCI and experimental day. Considering the 285 effects of these variables, we estimated the adjusted- $R$ scores -adjusted $R$ after controlling for 286 the confounding fixed effects (Dingemanse \& Dochtermann, 2013). The sequential 
287 hermaphroditism of the pearly razorfish inevitably implies that body size and sex are correlated, 288 creating a co-linearity conflict in our GLMM. We selected the fish body size (in $\mathrm{cm}$ ) as a 289 continuous variable to adjust the GLMM, but the results are discussed as the body size / sexual 290 effect. We computed the RCI, a measure of the internal state of the individual, as the ratio

291 between the observed fresh weight (in g) and the predicted weight from an independently 292 estimated length-weight relationship for the species (Battaglia et al., 2010) following the 293 protocol in Morgan, (2004). The RCI was preferred because, in contrast to Fulton's condition 294 index, it is independent of body size (Morgan, 2004). Finally, the experimental day (an integer 295 number from 1 to 4, assigned depending on the actual experimentation date) was included in the 296 model to control for potential effects of captivity (e.g., acclimation effect). The three variables 297 were scaled and mean-centred as they represented factors in very different units. The fixed 298 structure of the full model (considering all variables) was reduced using bidirectional elimination 299 (i.e. 'step-by-step' backward reduction, which is a combination of the backward and forward 300 stepwise selection) until the lowest Deviance Information Criteria (DIC) was attained (we 301 assumed a cut-off of two points in the process).

303 The full GLMM considered a random structure based on a nested variable attributable to the 304 individual nested in experimental weeks (as described in the experimental protocol). The 305 reduction of the model was based on bidirectional elimination, the same strategy used for the 306 fixed structure of the GLMM. The parameters and the Bayesian Credibility Intervals (BCI, 2.5\% 307 and $97.5 \%$ ) of the LMMs were estimated using a Bayesian approach with the default settings 308 from the library MCMCglmm (Hadfield, 2010). In all cases, convergence of the chains was 309 attained and checked by plotting the distribution of the residuals. A transformation (natural 
310 logarithm) was applied to the cases where the normality of the residuals was not fulfilled. We

311 used the reduced GLMM to compute adjusted- $R$ scores for each fish. The BCI of the adjusted- $R$

312 scores was interpreted to detect the presence of behavioural types. A likelihood ratio test (LRT)

313 was used to calculate the significance of the adjusted- $R$. According to the LRT, the reduction in

314 the DIC ( $\triangle \mathrm{DIC})$ provided by the GLMM where $\mathrm{Vind}_{0}$ was constrained to 0 was used to detect

315 significant $\operatorname{Vind}_{0}$. Adjusted- $R$ scores were considered significant when comparing the

316 unconstrained GLMM to the constrained GLMM resulted in DIC reductions larger than 2. To

317 check if there was an effect of TL within the same sex, we separately analysed the data

318 corresponding to the females $(n=37)$ following the same protocol explained above. We could

319 not do this for the males due to the small sample size $(\mathrm{n}=12)$.

320

$321 \quad$ 2.6. Ethical notes

322 This study was positively evaluated by the Ethical Committee for Animal Experimentation of the 323 University of the Balearic Islands (references for the protocols CEEA 97/0718 and CEEA 324 107/01/19), and authorised by the Animal Research Ethical Committee of the Conselleria 325 d'Agricultura, Pesca i Alimentació and the Direcció General de Pesca i Medi Marí of the

326 Government of the Balearic Islands (reference for the authorisations ES070050000502 and 327 2019/20/AEXP).

328

329

\section{RESULTS}

330

\subsection{Sample size and general results}

331 Aggressiveness was successfully scored (at least twice) for all 49 individuals. In all tests, the

332 three metrics for aggressiveness (number of bites, number of rams and number of charges) were 
333 successfully quantified. The first two components of the PCA applied to the three

334 aggressiveness' metrics are shown in Figure 3. The PC1 explained $87.6 \%$ of the total variance,

335 showing a correlation betwenn the three variables (Figure 3). We therefore selected the PC1

336 scores as a unique measure for aggressiveness. The aggressiveness score defined by the PC1 was

337 normalised to a natural number by multiplying by a factor of -1 , so the higher scores described

338 the more aggressive individuals with larger number of bites, number of rams and number of

339 charges (Figure 3), and the lower scores described lower levels of antagonistic behaviours in

340 front of the mirror (Figure 3).

341

342 3.2. Effect of contextual variables in the aggressiveness score

343 The estimates and confidence intervals (CI) for the effects of the contextual variance on the

344 aggressiveness score of the pearly razorfish are shown in Table 1. The GLMM suggests that

345 neither the body size nor the sex has a significant effect on the aggressiveness of the pearly

346 razorfish (Table 1 and Figure 4). Results were consistent in the female-only data set being the

347 scores of small and large females similar (Table 2 and Figure 5). The individuals presented a

348 mean \pm s.d. RCI of $1.28 \pm 3.65$ (range of -9.53 to 13.07 ). The results regarding the RCI were also

349 non-significant in both GLMMs, suggesting that the condition of the fish was not related to its

350 aggressiveness score (Table 1). Finally, the effect of the experimental day was also non-

351 significant in both models, rejecting any effect of the days under laboratory conditions on

352 aggressiveness levels (Table 1). In both fitted GLMMs (complete and female-only data set), only

353 the ID of the individual (between-individual variance) was retained in the random structure of

354 the model according to the DIC optimisation, rejecting an among-week effect. 
357 The aggressiveness scores for complete data set averaged $33.38 \pm 91.15$ (Figure 4), and their 358 adjusted- $R$ score was 0.57 with a BCI of $[0.44-0.60]$ (Table 1 ). For the female-only data set, the 359 average aggressiveness was $28.98 \pm 85.38$ (Figure 5), and their adjusted- $R$ score 0.36 with a BCI 360 of $[0.27-0.48]$ (Table 2). The fit and the DIC of the constrained (DICc) GLMM suggested that

361 this adjusted- $R$ score could be considered significant in both cases, evidencing the existence of 362 aggressive and non-aggressive behavioural types (Table 1 and 2). The model shows that the $R$ 363 was significant: $\mathrm{DIC}=558.22$ and $\mathrm{DICc}=641.32($ for the complete data set. Table 1$)$ and DIC $=$ 364481.33 and DICc $=446.62$ (for the female-only data set, Table 2). This was reflected by a large

365 phenotypic variation ranging from individuals who bit on average 350 times per test (for 366 example, XN0035, Figure 4) and individuals that did not interact with the mirror (for example, 367 XN0047, Figure 4), independently of their sex and size.

\section{DISCUSSION}

370 This work is the first behavioural study considering captive razorfishes. Aggressiveness was

371 tested on 49 pearly razorfish and our results showed a $R$ score for aggressiveness of 0.54 [0.48 -

$3720.61]$. The $R$ score was statistically significant, demonstrating that consistent differences among

373 individuals exist and corroborating the existence of aggressiveness-related behavioural types in

374 the pearly razorfish. Most importantly, assuming a $R$ score of 0.54 (average of our values), 49

375 individuals (with an average of three experimental trials per individual) provided an accuracy

376 (root mean square error) of $\sim 0.1$ for estimating phenotypic behavioural variation, and a power

377 greater than $\sim 0.8$ for estimating behavioural syndromes following Dingemanse and Dochtermann

378 (2013). The variables considered in this study (body size and sex, RCI and experimental day) did 
379 not affect on the aggressiveness score of the pearly razorfish. Therefore, we rejected our initial

380 hypotheses that males were more aggressive than females and that the most aggressive

381 individuals were those with the lowest RCI. These results suggest that aggressiveness is intrinsic

382 to the individual's life history, and that aggressiveness may be involved in different aspects of

383 the ecology and biology of the pearly razorfish. Moreover, the fast acclimatisation, the low-stress

384 levels observed, and the fact that the individuals responded to the mirror, confirms that our 385 system is adequate to measure aggressiveness in pearly razorfish, making this species a 386 successful candidate for behavioural ecology studies in marine fish.

388 Our results suggest that the mirror test is an excellent methodology to measure aggressiveness in

389 the pearly razorfish, providing real measures of agonistic interactions in front of a conspecific

390 individual. The mirror test has been widely used in fish, with excellent results, which show the

391 optimisation of this test to measure aggressive behaviours (Francis, 1990; Grantner \& Taborsky,

392 1998; Rowland, 1999; Budaev, Zworykin \& Mochek, 1999; Vøllestad \& Quinn, 2003; Pham et

393 al., 2012). Since fish, like many other taxa, do not recognise their reflection in the mirror

394 (Gallup, 1968) -at least if they are exposed to such stimulus for short periods of time as when

395 performing a behavioural test (Kohda et al., 2019)- the mirror test entails reinforced

396 aggressiveness given that it provides the continuous stimulation by an opponent (Gallup, 1968;

397 Rowland, 1999). Furthermore, the mirror test is also used in territoriality studies to determine

398 which male is in a better position to feed and reproduce. In our species, behaviours such as

399 territoriality and dominance of some males over others have been described (Scotti \& Foster,

400 2007; Snekser et al., 2009; McGhee \& Travis, 2010; Blowes, Pratchett \& Connolly, 2013).

401 Overall, the mirror test has some advantages compared to other methodologies such as the 
402 opponent test (Rhoad, Kalat \& Klopfer, 1975). The number of experimental individuals used is

403 reduced to the focal individuals. This is particularly relevant in our study species because

404 individuals bury in the sand when they feel threatened, thus making the capture process within

405 the tank challenge. Placing the "opponent" and the focal individual side by side during the trials

406 would significantly increase the individuals' stress and anxiety, affecting on the results obtained

407 during the behavioural testing. Moreover, the opponent test requires an accurate selection of

408 opponent fish because size, sex and behaviour may influence the focal individual's response

409 (Earley, Hsu \& Wolf, 2000; Wilson et al., 2011). If different opponents are used, it becomes

410 challenging to compare the results. Obtaining aggressiveness scores for the focal individuals

411 regardless of the opponent's characteristics would require a vast sample size to repeat the

412 experiment with multitude of different opponents.

413

414 From assessing aggressiveness in our population, we have obtained a relatively high $R$ score

415 (0.54) compared with other studies. The average $R$ across 98 species is 0.37 (Bell, Hankison \&

416 Laskowski, 2009). Other studies, however, have reported higher $R$ scores. In the blue catfish

417 (Luciana godei), an $R$ score of 0.72 was obtained for aggressive behaviours (McGhee \& Travis,

418 2010). In the zebrafish, specific $R$ scores were recorded for different metrics of aggressiveness:

419 an $R$ score of 0.39 was obtained for overall aggressive behaviours (Roy \& Bhat, 2018), an $R$

420 score of 0.56 for the number of bites (Way et al., 2015), and a lack of repeatability was reported

421 for mirror tests experiments in zebrafish (Sbragaglia et al., 2019). These differences suggest that

422 the $R$ score is sensitive to the selected aggressiveness metric. In our study, a PCA was performed

423 to obtain an aggressiveness score (PC1) that was the result of reducing the dimensions of our

424 measured variables. The PC1 explained $87.9 \%$ of the variability of the data set, and it was 
425 mostly related to the number of bites (Figure 3), which seems to be the most relevant metric to

426 quantify aggressiveness at the individual level according to previous work (Way et al., 2015) and

427 our findings. Our results demonstrated that aggressiveness is a constant behaviour maintained

428 between individuals and overtime in the pearly razorfish (Table 1 and Figure 4 for the complete

429 data set; Table 2 and Figure 5 for female-only data set)

430

431 Differences in aggressiveness were not related to body size. Since the pearly razorfish is a 432 sequential hermaphrodite, size and sex are correlated, and thus the lack of effect should be

433 jointly interpreted. Other studies revealed a positive relationship between aggressiveness and size 434 in different species such as the lion-headed cichlid, (Steatocranus casuarius), (Budaev, 435 Zworykin \& Mochek, 1999); the green swordtails, (Wilson et al., 2011) and the Midas cichlid, 436 (Francis, 1990). In general, it has been found that aggressiveness plays an important role in 437 social structure, where the most aggressive males have a higher position in the mating hierarchy 438 (McGhee \& Travis, 2010). This could be the case of the pearly razorfish, a species that lives in 439 harems formed by a male and several females (Espino et al., 2015) and where there is intra440 sexual but not between-sexes competition. Male and female territories usually overlap, 441 suggesting that the shared space is used for reproduction (Shen \& Clark, 2016). Likely, male 442 aggression is probably related to their position in the social structure and their resource holding 443 potential (RHP), defined as the ability to win a contest and maintain earned resources (Parker, 444 1974; Hurd, 2006). RHP depends on the size of the opponents, and the motivation, physiological 445 state and behaviour of the focal individual (Parker, 1974; Nijman \& Heuts, 2000). Thus, 446 aggressiveness on pearly razorfish might be playing an essential role in the structure of the 447 population. 
449 Our initial hypothesis that the RCI was negatively correlated with aggression was also rejected.

450 Individual behavioural responses may modulate internal energetic fluxes. Since aggressive

451 behaviours are energetically very demanding (Katano \& Iguchi, 1996), highly aggressive

452 individuals may have a poor condition because they invest a lot of time and energy in

453 antagonistic behaviours (Grantner \& Taborsky, 1998).-Most studies agree that aggressive

454 behaviours are energetically costly, and different internal growth rates, maturity stages and

455 metabolic rates are negatively related to aggressiveness (Cutts, 1998; Vøllestad \& Quinn, 2003).

456 In the present study, we did not find a relationship between the RCI and the aggressiveness

457 score. This could be since metabolic levels may vary between seasons due to food availability,

458 while behaviour remains more constant over time (Vøllestad \& Quinn, 2003; Bouwhuis et al.,

459 2014). We also considered the effect of the experimental day in our GLMM to control for

460 potential effects of captivity. Visually, individuals displayed normal behaviour after the three

461 days of acclimation. In the same way, fishes could have habituated to the mirror during the

462 experiments. Studies have shown that continuous exposure to stimuli over a series of consecutive

463 days can decrease the level of behavioural reactivity due to habituation. Long acclimatisation

464 could reduce fish activity levels (O’Neill et al., 2018), decrease exploration rates and increase

465 individual's boldness over time (Adriaenssens \& Johnsson, 2011). The effect of acclimatisation

466 has also been reported on aggressiveness; in fact, the number of aggressive interactions can

467 decrease significantly across trials (Roy \& Bhat, 2018). In the pearly razorfish, however, the 468 correlation between experimental day and aggressiveness score was not statistically significant, 469 rejecting any acclimation or habituation effect. 
471 Our results suggest that aggressiveness is a significant individual intrinsic factor, and we can

472 derive some potential physiological and ecological consequences from the existence of

473 aggressiveness behavioural types in the pearly razorfish. Aggressiveness has been closely related

474 to growth and metabolic rates (Cutts, 1998; Vøllestad \& Quinn, 2003), reproduction

475 (Hirschenhauser et al., 2008; Snekser et al., 2009; McGhee \& Travis, 2010) and dominance in

476 social structures (Grantner \& Taborsky, 1998; Earley, Hsu \& Wolf, 2000; May \& Mercier, 2007;

477 Pham et al., 2012; Blowes, Pratchett \& Connolly, 2013). Therefore, aggressiveness could be

478 linked to the life history of the pearly razorfish affecting the individual fitness and its position

479 within its social group. Instead of expecting a difference in aggressiveness related to sex, size or

480 condition, we could expect differences in aggressiveness linked to the social structure of this

481 species. We could also expect aggressiveness to be related to the formation and maintenance of

482 individual territories. Following this idea, the most aggressive males would be the ones obtaining

483 the best feeding patches and the highest quality mates. Similarly, females could compete with

484 each other for the best males. These hypotheses deserve more attention and require the

485 combination of measurements of aggressiveness scores in the laboratory alongside with the

486 measurement of territory sizes in the field.

487

488 The relationship between dominance and aggressiveness extends across taxa (May \& Mercier, 489 2007; Snekser et al., 2009). For instance, in salmonid species, the most aggressive individuals

490 have better competitive capabilities, making them dominant and monopolize high-quality 491 territories (Huntingford, 1998). Aggressive individuals defend high-quality territories since the

492 benefit obtained from this territory is greater than the cost of defending it (Bacon, Ball \&

493 Blackwell, 1991; Stamps \& Krishnan, 1999). Aggressiveness plays a crucial role in obtaining 
494 and maintaining territories. Similarly, the attack of an intruder to obtain a territory will cease if

495 the benefit obtained is not enough (Stamps \& Buechner, 1985; Stamps \& Krishnan, 1999).

496 Animals' ability to achieve and defend their territories depends mostly on their behaviour

497 (Stamps, 1994; Dingemanse \& Réale, 2005). Therefore, our work demonstrating the existence of

498 aggressive behavioural types provides a novel perspective on understanding the territorial

499 societies of the pearly razorfish.

500

501 Furthermore, it is necessary to understand how disturbances affect fish behaviour and

502 populations (Biro, Post \& Booth, 2007; Biro, Beckmann \& Stamps, 2010). The study of

503 behavioural types is essential to understand ecological patterns and population dynamics (Conrad

504 et al., 2011; Sih et al., 2012). Intraspecific variability in fish behaviour is closely related to the

505 resilience of populations to environmental disturbances (e.g. climate change) (Wolf et al., 2007).

506 It has been shown that anthropic disturbances such as fishing have important effects on 507 behavioural types (Biro et al., 2007, Biro et al., 2010). Fishing is one of the biggest drivers of 508 evolution in fish species (Sullivan, Bird \& Perry, 2017). Fish vulnerability to fishing is a 509 complex phenomenon in which many processes are involved, and in which behaviour plays a

510 significant role (Arlinghaus et al., 2017). It has been demonstrated that fishers select for certain

511 behaviours (activity, awakening times) in wild pearly razorfish populations (Alós et al., 2016;

512 Martorell-Barceló, Campos-Candela \& Alós, 2018). In other species, fishing selects against bold 513 and aggressive individuals (Arlinghaus et al., 2017). This could also be the case in the pearly

514 razorfish populations. Since the most aggressive individuals tend to take more risks in dangerous

515 situations, their removal would likely reduce the likelihood of them being killed by natural

516 predators, (Sih et al., 2012; Arlinghaus et al., 2017). In this way, the intraspecific variability of 
517 aggressiveness in the pearly razorfish can be reduced in exploited populations, affecting a

518 multitude of ecosystem processes with significant ecological and economic consequences. For all

519 the reasons mentioned above, this research deserves further attention and the development of

520 experimental protocols involving laboratory scoring and wild assessment of behaviour in real 521 exploited populations.

522

523 In this study, we provide for the first time a behavioural type scoring for the pearly razorfish.

524 However, our research has some limitations. First, we obtained the experimental fish via 525 experimental fishing, and we provide evidence that fishing selects a type of behaviour, skewing 526 the sampled population. Despite this, our individuals were obtained from a population located in 527 a Marine Protected Area where fishing is not allowed, and therefore the entire repertoire of 528 behaviours should be vulnerable. Furthermore, the sampling equipment used was based on natural baits. Generally, the link between hook and line vulnerability and aggressiveness has 530 been found in fisheries using artificial lures (Lennox et al. 2017). Therefore, in our opinion, our

531 sample was representative of the studied population. Second, we tested a small sample of males

$532(\mathrm{~N}=12)$. It is possible that increasing male's sample size would translate into significant 533 differences in aggressiveness associated with the size. In the present study we only considered 534 aggressiveness. However, in future works, it would be interesting to study behavioural 535 syndromes between aggressiveness and other behavioural types, including chronotypes.

\section{CONCLUSIONS}

538 Our work shows, for the first time, the presence of behavioural types in the pearly razorfish, 539 provided by a significant and high repeatability score. Body size (correlated with sex), RCI and 
540 the experimental day did not have a significant effect on the aggressive behaviours of the pearly

541 razorfish. Aquariums with a closed water system and the mirror test have proven successful as a

542 methodology for studying aggressive behaviour in the pearly razorfish. The results obtained from

543 the mirror test revealed consistent differences in aggressiveness levels among individuals. This is

544 the first behavioural study on the pearly razorfish under controlled laboratory conditions, its fast

545 acclimatisation and low-stress levels observed make this species a successful candidate for

546 behavioural studies of marine fish. This study also provides novel information on fish

547 aggressiveness. We believe this is the first step for a better understanding of the pearly razorfish

548 personality and its implications in ecological and evolutionary processes.

549

550 Acknowledgements

551 We thank the staff of the Marine Research and Aquaculture Laboratory of Andratx (LIMIA) for

552 the help received and for letting us use their facilities for this study. This work is a contribution

553 of the joint research unit IMEDEA - LIMIA. This work also received funding from the

554 CLOCKS R\&D Project (grant no. PID2019-104940GA-I00) funded by the MICINN and the

555 Agencia Estatal de Investigación, the intramural research project JSATS (grant no.

556 PIE202030E002) funded by the MICINN and the Spanish National Research Council (CSIC)

557 and from the Cronofihs project (grant no. CEEA97/97/28) funded by the Balearic Island

558 Government General Direction of Innovation and Research. Martina Martorell-Barceló was

559 supported by an FPI predoctoral fellowship (ref. FPI/2167/2018) from the Balearic Islands

560 Government General Direction of Innovation and Research. Josep Alós was supported by a

561 Ramon y Cajal Grant (grant no. RYC2018-024488-I) funded by the Spanish Ministry of Science 
562 and Innovation (MICINN). Margarida Barcelo-Serra was supported by a MSCA-IF (grant num.

563 WildFishGenes-891404). 


\section{Literature cited:}

566 Adriaenssens B, Johnsson JI. 2011. Learning and context-specific exploration behaviour in

567 hatchery and wild brown trout. Applied Animal Behaviour Science 132:90-99. DOI:

$568 \quad$ 10.1016/j.applanim.2011.03.005.

569 Alós J, Cabanellas-Reboredo M, Lowerre-Barbieri S. 2012. Diel behaviour and habitat utilisation

570 by the pearly razorfish during the spawning season. Marine Ecology Progress Series

571 460:207-220. DOI: 10.3354/meps09755.

572

573

574

575

576

577

578

579

580

581

582

583

584

585

586

587

Alós J, Martorell-Barceló M, Campos-Candela A. 2017. Repeatability of circadian behavioural variation revealed in free-ranging marine fish. Royal Society Open Science 4:160791. DOI: 10.1098/rsos.160791.

Alós J, Palmer M, Rosselló R, Arlinghaus R. 2016. Fast and behavior-selective exploitation of a marine fish targeted by anglers. Scientific Reports 6:38093. DOI: 10.1038/srep38093.

Andrews E. 1966. Slate-Colored Junco Response to Mirror. Bird-Banding 37:206. DOI: $10.2307 / 4511292$.

Arlinghaus R, Laskowski KL, Alós J, Klefoth T, Monk CT, Nakayama S, Schröder A. 2017. Passive gear-induced timidity syndrome in wild fish populations and its potential ecological and managerial implications. Fish and Fisheries 18:360-373. DOI: 10.1111/faf.12176.

Bacon PJ, Ball F, Blackwell P. 1991. A model for territory and group formation in a heterogeneous habitat. Journal of Theoretical Biology 148:445-468. DOI: 10.1016/S00225193(05)80231-0.

Baenninger R. 1968. Catechol amines and social relations in siamese fighting fish. Animal Behaviour 16:442-447. DOI: 10.1016/0003-3472(68)90038-9.

Balzarini V, Taborsky M, Wanner S, Koch F, Frommen JG. 2014. Mirror, mirror on the wall: 
The predictive value of mirror tests for measuring aggression in fish. Behavioral Ecology and Sociobiology 68:871-878. DOI: 10.1007/s00265-014-1698-7.

590 Battaglia P, Castriota L, Consoli P, Falautano M, Romeo T, Andaloro F. 2010. Age and growth 591 of pearly razorfish, Xyrichtys novacula (Linnaeus 1758), in the central Mediterranean Sea. 592 Journal of Applied Ichthyology 26:410-415. DOI: 10.1111/j.1439-0426.2009.01383.x.

593 Bell AM. 2005. Behavioural differences between individuals and two populations of stickleback 594 Behavioural differences between individuals and two populations of stickleback (Gasterosteus aculeatus). Journal of Evolutionary Biology 18:464-473. DOI: 10.1111/j.1420-9101.2004.00817.x.

Bell AM, Hankison SJ, Laskowski KL. 2009. The repeatability of behaviour: a meta-analysis. Animal Behaviour 77:771-783. DOI: 10.1016/j.anbehav.2008.12.022.

Bell AM, Henderson L, Huntingford FA. 2010. Behavioral and respiratory responses to stressors in multiple populations of three-spined sticklebacks that differ in predation pressure. Journal of Comparative Physiology B: Biochemical, Systemic, and Environmental Physiology 180:211-220. DOI: 10.1007/s00360-009-0395-8.

Bell AM, Stamps JA. 2004. Development of behavioural differences between individuals and 604 605 populations of sticklebacks, Gasterosteus aculeatus. Animal Behaviour 68:1339-1348.

Biro PA, Beckmann C, Stamps JA. 2010. Small within-day increases in temperature affects boldness and alters personality in coral reef fish. Proceedings of the Royal Society B: Biological Sciences 277:71-77. DOI: 10.1098/rspb.2009.1346. in whole-lake experiments. Proceedings of the National Academy of Sciences 104:9715- 
9719. DOI: $10.1073 /$ pnas.0701638104.

612 Blowes SA, Pratchett MS, Connolly SR. 2013. Heterospecific aggression and dominance in a 613 guild of coral-feeding fishes: The roles of dietary ecology and phylogeny. The American $614 \quad$ Naturalist 182:157-168. DOI: 10.1086/670821.

615 Bouwhuis S, Quinn JL, Sheldon BC, Verhulst S. 2014. Personality and basal metabolic rate in a 616 wild bird population. Oikos 123:56-62. DOI: 10.1111/j.1600-0706.2013.00654.x.

617 Budaev S V, Zworykin DD, Mochek AD. 1999. Consistency of individual differences in 618 behaviour of the lion-headed cichlid, Steatocarnus casuarius. Behavioural Processes 619 48:49-55. DOI: 10.1016/S0376-6357(99)00068-6.

620 Candi G, Castriota L, Andaloro F, Finoia MG, Marino G. 2004. Reproductive cycle and sex 621 inversion in razor fish, a protogynous labrid in the southern Mediterranean Sea. Journal of 622 Fish Biology 64:1498-1513. DOI: 10.1111/j.0022-1112.2004.0404.x.

623 Cardinale M, Colloca F, Ardizzone GD. 1997. Feeding ecology of Mediterranean razorfish 624 Xyrichtyhys novacula in the Tyrrenian Sea (Central Mediterranean Sea). Journal of Applied 625 Ichthyology 13:105-111. DOI: 10.1111/j.1439-0426.1997.tb00109.x.

626 Cardinale M, Colloca F, Ardizzone GD. 1998. Growth and reproduction of Xyrichtys novacula 627 (Pisceas: Labridae) in the Mediterranean Sea. Scientia Marina 62:193-201. DOI: $628 \quad 10.3989 /$ scimar.1998.62n3193.

629 Careau A V, Thomas D, Humphries MM, Réale D, Oikos S, May N. 2008. Energy metabolism 630 and animal personality Oikos 117:641-653. DOI: 10.1111/j.2008.0030-1299.16513.x.

631 Castriota L, Scarabello MP, Finoia MG, Sinopoli M, Andaloro F. 2005. Food and feeding habits 632 of pearly razorfish, Xyrichtys novacula (Linnaeus, 1758), in the southern Tyrrhenian Sea: 633 variation by sex and size. Environmental Biology of Fishes 72:123-133. DOI: 
635 Cattelan S, Lucon-Xiccato T, Pilastro A, Griggio M. 2017. Is the mirror test a valid measure of 636 fish sociability? Animal Behaviour. DOI: 10.1016/j.anbehav.2017.03.009.

637 Conrad JL, Weinersmith KL, Brodin T, Saltz JB, Sih A. 2011. Behavioural syndromes in fishes: 638 a review with implications for ecology and fisheries management. Journal of Fish Biology 78:395-435. DOI: 10.1111/j.1095-8649.2010.02874.x.

640 Cote J, Fogarty S, Weinersmith K, Brodin T, Sih A. 2010. Personality traits and dispersal 641 tendency in the invasive mosquitofish (Gambusia affinis). Proceedings of the Royal Society 642 B: Biological Sciences 277:1571-1579. DOI: 10.1098/rspb.2009.2128.

643 Cutts C. 1998. Aggression and growth depression in juvenile Atlantic salmon: the consequences 644 of individual variation in standard metabolic rate. Journal of Fish Biology 52:1026-1037. 645 DOI: $10.1006 /$ jfbi.1998.0647.

646 Cutts CJ, Metcalfe NB, Taylor AC. 2002. Juvenile Atlantic Salmon (Salmo salar) with relatively 647 high standard metabolic rates have small metabolic scopes. Functional Ecology 16:73-78. 648 DOI: $10.1046 /$ j.0269-8463.2001.00603.x.

649 Dingemanse NJ, Dochtermann NA. 2013. Quantifying individual variation in behaviour: mixed650 effect modelling approaches. Journal of Animal Ecology 82:39-54. DOI: 10.1111/1365$651 \quad 2656.12013$.

652 Dingemanse NJ, Réale D. 2005. Natural selection and animal personality. Behaviour 142:1159653 1184. DOI: $10.1163 / 156853905774539445$.

654 Dore F, Lefebvre L, Ducharme R. 1978. Threat display in Betta splendens: Effects of water 655 condition and type of agonistic stimulation. Animal Behaviour 26:738-745. DOI:

$656 \quad 10.1016 / 0003-3472(78) 90140-9$. 
657 Earley RL, Hsu Y, Wolf LL. 2000. The use of standard aggression testing methods to predict 658 combat behaviour and contest outcome in Rivulus marmoratus dyads (Teleostei:

659 Cyprinodontidae). Ethology 106:743-761. DOI: 10.1046/j.1439-0310.2000.00586.x.

660 Espino F, Triay-Portella R, González JA, Haroun R, Tuya F. 2015. Population structure of the 661 pearly razorfish, Xyrichtys novacula (Actinopterygii: Labridae), in sand-seagrass mosaics: 662 spatial variation according to habitat features and sampling techniques. Scientia Marina 663 79:179-188. DOI: 10.3989/scimar.04219.05A.

664 Fischer W, Schneider M, Bauchot M-L. 1987. Fiches FAO d'identification des espèces pour les 665 besoins de la pêche : Mediterranée et Mer Noir / Volume II / Vertèbrés : Rajidae. In: Fiches 666 FAO d'identification des espèces pour les besoins de la pêche: Mediterranée et Mer Noir / $667 \quad$ Volume II / Vertèbrés.

668 Francis RC. 1990. Temperament in a fish: A longitudinal study of the development of individual 669 differences in aggression and social rank in the midas cichlid. Ethology 86:311-325. DOI:

670 10.1111/j.1439-0310.1990.tb00439.x.

671 Gallup GG. 1968. Mirror-image stimulation. Psychological Bulletin 70:782-793. DOI: $672 \quad 10.1037 / \mathrm{h} 0026777$.

673 Gosling SD. 2001. From mice to men: What can we learn about personality from animal 674 research? Psychological Bulletin 127:45-86. DOI: 10.1037/0033-2909.127.1.45.

675 Grantner A, Taborsky M. 1998. The metabolic rates associated with resting, and with the 676 performance of agonistic, submissive and digging behaviours in the cichlid fish 677 Neolamprologus pulcher (Pisces: Cichlidae). Journal of Comparative Physiology B:

678 Biochemical, Systemic, and Environmental Physiology 168:427-433. DOI:

679 $10.1007 / \mathrm{s} 003600050162$. 
680 Hadfield JD. 2010. MCMC methods for multi-response generalized linear mixed models: The 681 MCMCglmm R package. Journal of Statistical Software 33. DOI: 10.18637/jss.v033.i02.

682 Hirschenhauser K, Wittek M, Johnston P, Möstl E. 2008. Social context rather than behavioral 683 output or winning modulates post-conflict testosterone responses in Japanese quail 684 (Coturnix japonica). Physiology \& Behavior 95:457-463. DOI:

$685 \quad$ 10.1016/j.physbeh.2008.07.013.

686 Holtby LB, Swain DP, Allan GM. 1993. Mirror-elicited agonistic behaviour and body 687 morphology as predictors of dominance status in juvenile coho salmon (Oncorhynchus 688 kisutch). Canadian Journal of Fisheries and Aquatic Sciences 50:676-684. DOI: $689 \quad 10.1139 / \mathrm{f} 93-078$.

690 Huntingford F. 1998. Social status and growth rates as determinants of site attachment in 691 juvenile Atlantic salmon. Journal of Fish Biology 53:314-321. DOI:

$692 \quad$ 10.1006/jfbi.1998.0704.

693 Hurd PL. 2006. Resource holding potential, subjective resource value, and game theoretical 694 models of aggressiveness signalling. Journal of Theoretical Biology. DOI: $695 \quad$ 10.1016/j.jtbi.2006.01.001.

696 Hutchings JA, Bishop TD, McGregor-Shaw CR. 1999. Spawning behaviour of Atlantic cod, 697 Gadus morhua: evidence of mate competition and mate choice in a broadcast spawner. 698 Canadian Journal of Fisheries and Aquatic Sciences 56:97-104. DOI: 10.1139/f98-216. 699 Jolles JW, Briggs HD, Araya-Ajoy YG, Boogert NJ. 2019. Personality, plasticity and 700 predictability in sticklebacks: bold fish are less plastic and more predictable than shy fish. 701 Animal Behaviour 154:193-202. DOI: 10.1016/j.anbehav.2019.06.022.

702 de Jong K, Wacker S, Amundsen T, Forsgren E. 2009. Do operational sex ratio and density 
703 affect mating behaviour? An experiment on the two-spotted goby. Animal Behaviour 704 78:1229-1238. DOI: 10.1016/j.anbehav.2009.08.006.

705 Katano O, Iguchi K. 1996. Individual differences in territory and growth of ayu, Plecoglossus 706 altivelis (Osmeridae). Canadian Journal of Zoology 74:2170-2177. DOI: 10.1139/z96-245.

707 Kohda M, Hotta T, Takeyama T, Awata S, Tanaka H, Asai J, Jordan AL. 2019. If a fish can pass

708 the mark test, what are the implications for consciousness and self-awareness testing in $709 \quad$ animals? PLOS Biology 17:e3000021. DOI: 10.1371/journal.pbio.3000021.

710 Lahti K, Laurila A, Enberg K, Piironen J. 2001. Variation in aggressive behaviour and growth

711 rate between populations and migratory forms in the brown trout, Salmo trutta. Animal

712 Behaviour 62:935-944. DOI: 10.1006/anbe.2001.1821.

713 Lennox RJ, Alós J, Arlinghaus R, Horodysky A, Klefoth T, Monk CT, Cooke SJ. 2017. What

714 makes fish vulnerable to capture by hooks? A conceptual framework and a review of key

715 determinants. Fish and Fisheries 18:986-1010. DOI: 10.1111/faf.12219.

716 Marconato A, And VT, Marin G. 1995. The mating system of Xyrichthys novacula: sperm

717 economy and fertilization success. Journal of Fish Biology 47:292-301. DOI:

$718 \quad 10.1111 / \mathrm{j} .1095-8649.1995 . t b 01896 . x$.

719 Martorell-Barceló M, Campos-Candela A, Alós J. 2018. Fitness consequences of fish circadian

720 behavioural variation in exploited marine environments. PeerJ 6:e4814. DOI:

$721 \quad 10.7717 /$ peerj.4814.

722 May HY, Mercier AJ. 2007. Duration of socialization influences responses to a mirror: responses

723 of dominant and subordinate crayfish diverge with time of pairing. Journal of Experimental 724 Biology 210:4428-4436. DOI: 10.1242/jeb.011288.

725 McGhee KE, Travis J. 2010. Repeatable behavioural type and stable dominance rank in the 

bluefin killifish. Animal Behaviour 79:497-507. DOI: 10.1016/j.anbehav.2009.11.037.

727

728

729

730

731

732

733

734

735

736

737

738

739

740

741

742

743

744

745

746

747

748

Meliska CJ, Meliska JA, Peeke HVS. 1980. The relationship of mirror-elicited display to combat behaviors in Betta splendens. Behavioral and Neural Biology 30:207-217. DOI: 10.1016/S0163-1047(80)91089-4.

Millot S, Cerqueira M, Castanheira M-F, Øverli Ø, Oliveira RF, Martins CIM. 2014. Behavioural stress responses predict environmental perception in european sea bass (Dicentrarchus labrax). PLoS ONE 9:e108800. DOI: 10.1371/journal.pone.0108800.

Morgan MJ. 2004. The relationship between fish condition and the probability of being mature in American plaice (Hippoglossoides platessoides). ICES Journal of Marine Science 61:6470. DOI: 10.1016/j.icesjms.2003.09.001.

Nakagawa S, Schielzeth H. 2010. Repeatability for Gaussian and non-Gaussian data: a practical guide for biologists. Biological Reviews 85.4: 935-956. DOI: 10.1111/j.1469185X.2010.00141.X.

Nemtzov SC, Clark E. 1994. Intraspecific egg predation by male razorfishes (Labridae) during broadcast spawning: Filial cannibalism or intra-pair parasitism? Bulletin of marine science 55.1 (1994): 133-141. DOI: https://www.researchgate.net/publication/233665638.

Nijman V, Heuts BA. 2000. Effect of environmental enrichment upon resource holding power in fish in prior residence situations. Behavioural Processes. 49.2: 77-83. DOI: 10.1016/S03766357(00)00078-4.

Nomakuchi S, Park PJ, Bell MA. 2009. Correlation between exploration activity and use of social information in three-spined sticklebacks. Behavioral Ecology 20:340-345. DOI: 10.1093/beheco/arp001.

O’Connor CM, Reddon AR, Ligocki IY, Hellmann JK, Garvy KA, Marsh-Rollo SE, Hamilton 
IM, Balshine S. 2015. Motivation but not body size influences territorial contest dynamics in a wild cichlid fish. Animal Behaviour 107:19-29. DOI: 10.1016/j.anbehav.2015.06.001.

751

752

753

754

755

756

757

758

759

760

761

762

763

764

765

766

767

768

769

770

771

O’Neill SJ, Williamson JE, Tosetto L, Brown C. 2018. Effects of acclimatisation on behavioural repeatability in two behaviour assays of the guppy Poecilia reticulata. Behavioral Ecology and Sociobiology 72:166. DOI: 10.1007/s00265-018-2582-7.

Parker GA. 1974. Assessment strategy and the evolution of fighting behaviour. Journal of Theoretical Biology. 47.1: 223-243 DOI: 10.1016/0022-5193(74)90111-8.

Pham M, Raymond J, Hester J, Kyzar E, Gaikwad S, Bruce I, Fryar C, Chanin S, Enriquez J, Bagawandoss S, Zapolsky I, Green J, Michael Stewart A, Robison BD, Kalueff A V. 2012. Assessing social behavior phenotypes in adult zebrafish: shoaling, social preference, and mirror biting test. Zebrafish Protocols for Neurobehavioral Research. Totowa, NJ: Humana Press. DOI: 10.1007/978-1-61779-597-8_17.

Réale D, Reader SM, Sol D, McDougall PT, Dingemanse NJ. 2007. Integrating animal temperament within ecology and evolution. Biological Reviews 82:291-318. DOI: 10.1111/j.1469-185X.2007.00010.x.

Rehage JS, Sih A. 2004. Dispersal behavior, boldness, and the link to invasiveness: A comparison of four gambusia species. Biological Invasions 6:379-391. DOI:

$$
\text { 10.1023/B:BINV.0000034618.93140.a5. }
$$

Rhoad KD, Kalat JW, Klopfer PH. 1975. Aggression and avoidance by Betta splendens toward natural and artificial stimuli. Animal Learning \& Behavior 3:271-276. DOI: 10.3758/BF03213443.

Rowland WJ. 1999. Studying visual cues in fish behavior: A review of ethological techniques. Environmental Biology of Fishes 56:285-305. DOI: 10.1023/A:1007517720723. 
772 Roy T, Bhat A. 2018. Repeatability in boldness and aggression among wild zebrafish (Danio

773 rerio) from two differing predation and flow regimes. Journal of Comparative Psychology

774 132:349-360. DOI: 10.1037/com0000150.

775 Ryan White J. 2015. The role of boldness and other personality traits in the ecology of juvenile

776 marine fishes. Doctoral dissertation, James Cook University.

777 Sbragaglia V, Alós J, Fromm K, Monk CT, Díaz-Gil C, Uusi-Heikkilä S, Honsey AE, Wilson

778 ADM, Arlinghaus R. 2019. Experimental size-selective harvesting affects behavioral types

779 of a social fish. Transactions of the American Fisheries Society. 148.3: 552-568. DOI:

$780 \quad 10.1002 /$ tafs. 10160.

781 Scotti M-AL, Foster SA. 2007. Phenotypic plasticity and the ecotypic differentiation of

782 aggressive behavior in Threespine stickleback. Ethology 113:190-198. DOI:

$783 \quad$ 10.1111/j.1439-0310.2006.01311.x.

784 Shen D, Clark E. 2016. Territorial and reproductive behavior of the three Caribbean Razorfishes

785 of the genus Xyrichtys (Labridae) at Bonaire. International Journal of Ichthyology 22:33-

78659.

787 Sih A, Bell A, Johnson JC. 2004. Behavioral syndromes: an ecological and evolutionary

788 overview. Trends in Ecology \& Evolution 19:372-378. DOI: 10.1016/j.tree.2004.04.009.

789 Sih A, Cote J, Evans M, Fogarty S, Pruitt J. 2012. Ecological implications of behavioural

$790 \quad$ syndromes. Ecology Letters 15:278-289. DOI: 10.1111/j.1461-0248.2011.01731.x.

791 Snekser JL, Leese J, Ganim A, Itzkowitz M. 2009. Caribbean damselfish with varying territory

792 quality: correlated behaviors but not a syndrome. Behavioral Ecology 20:124-130. DOI:

793 10.1093/beheco/arn123.

794 Stamps J. 1994. Territorial behavior: testing the assumptions. In: Advances in the Study of 
Behavior. 173-232. DOI: 10.1016/S0065-3454(08)60354-X.

796 Stamps JA, Buechner M. 1985. The territorial defense hypothesis and the ecology of insular

797 vertebrates. The Quarterly Review of Biology 60:155-181. DOI: 10.1086/414314.

798 Stamps JA, Krishnan V V. 1999. A learning-based model of territory establishment. The

799 Quarterly Review of Biology 74:291-318. DOI: 10.1086/393163.

800 Sullivan AP, Bird DW, Perry GH. 2017. Human behaviour as a long-term ecological driver of

801 non-human evolution. Nature Ecology \& Evolution 1:0065. DOI: 10.1038/s41559-016-

8020065.

803 Taylor EB. 1990. Variability in agonistic behaviour and salinity tolerance between and within

804 two populations of juvenile chinook salmon, Oncorhynchus tshawytscha, with contrasting

805 life histories. Canadian Journal of Fisheries and Aquatic Sciences 47:2172-2180. DOI:

$806 \quad 10.1139 / \mathrm{f90}-242$.

807 Vøllestad LA, Quinn TP. 2003. Trade-off between growth rate and aggression in juvenile coho

808 salmon, Oncorhynchus kisutch. Animal Behaviour 66:561-568. DOI:

$809 \quad$ 10.1006/anbe.2003.2237.

810 Way GP, Ruhl N, Snekser JL, Kiesel AL, McRobert SP. 2015. A comparison of methodologies

811 to test aggression in zebrafish. Zebrafish 12:144-151. DOI: 10.1089/zeb.2014.1025.

812 Wilson AJ, de Boer M, Arnott G, Grimmer A. 2011. Integrating personality research and animal

813 contest theory: Aggressiveness in the green swordtail Xiphophorus helleri. PLoS ONE

814 6:e28024. DOI: 10.1371/journal.pone.0028024.

815 Wolf M, van Doorn GS, Leimar O, Weissing FJ. 2007. Life-history trade-offs favour the

816 evolution of animal personalities. Nature 447:581-584. DOI: 10.1038/nature05835. 


\section{Figure 1}

Representative diagram of the behavioural arenas.

Behavioural arenas were composed by an aquarium (container where the fish were held captive) connected to the filtering water system through a small sink. The tank contained seawater and sand that served as refuge for the fish. A filtration system was installed behind the tank, consisting of two sponges of different thickness, a biological filtration system and a skimmer responsible for removing the excess of urea. An airstone aerator, a water heater and a water pump were located in the filtration section. The recording system consisted of a Raspberry Pi computer and a Raspberry Pi camera. This system was mounted in front of the aquarium to have a frontal vision during the aggressiveness tests. On the photo, a fish can be seen swimming in an aquarium during the experimental period (diagram by Javier Sanllehi Hansson).
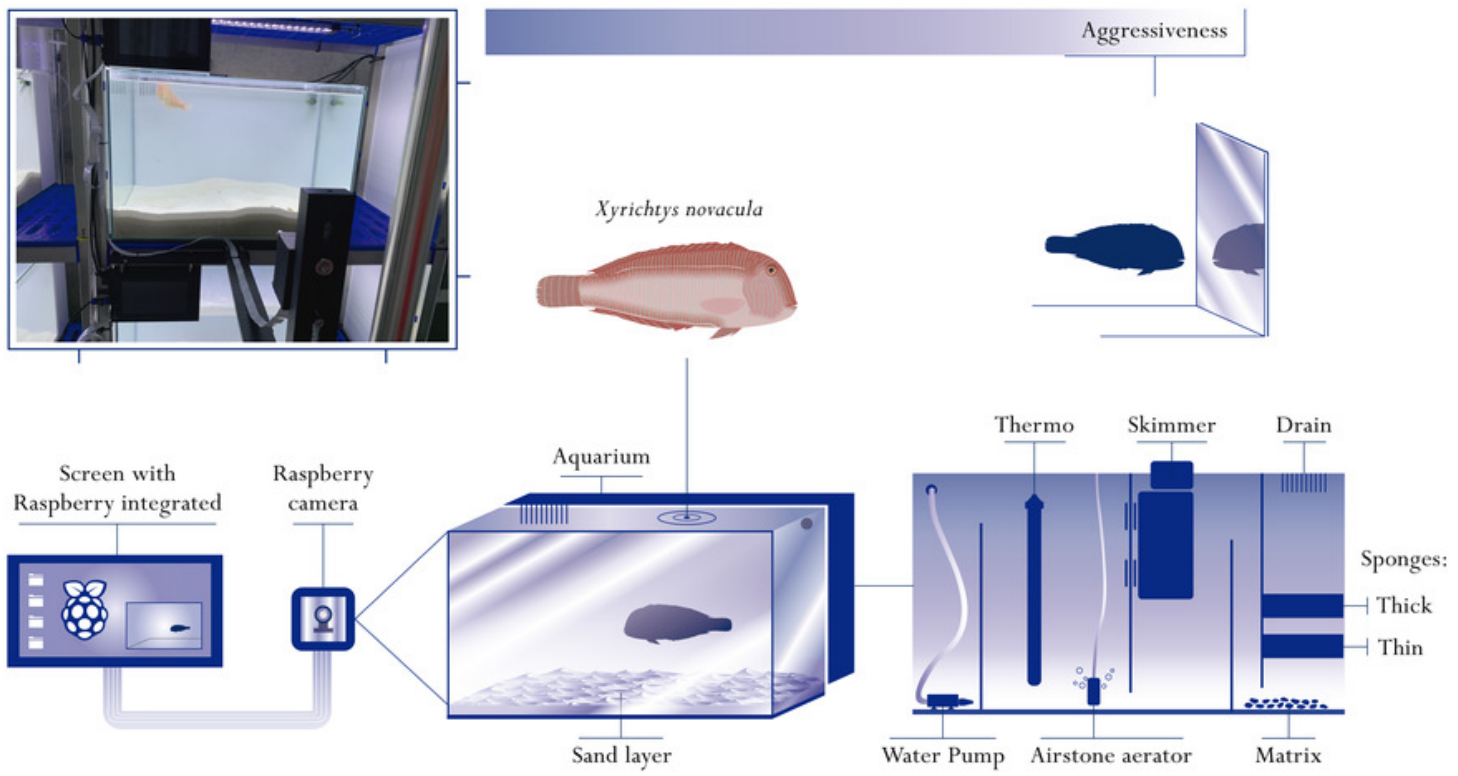
Figure 2

Graphical representation of the sample

(A) Histogram of the distribution of body sizes (in $\mathrm{cm}$ ) for the individuals considered in this study. (B) Boxplot of the weight differences (in g) between females and males. (C) Bar graph with the number of tests (number of individual samples) performed to each individual. (D) Scatterplot of the relative condition index $(\mathrm{RCl})$ for each individual. Males are represented in green and females in orange.

(A)

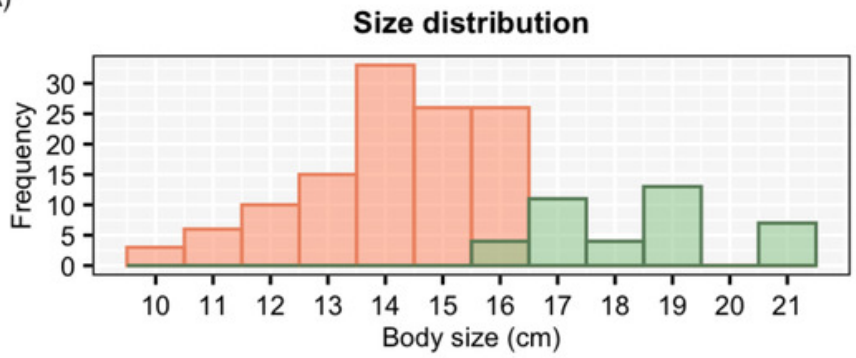

(B)

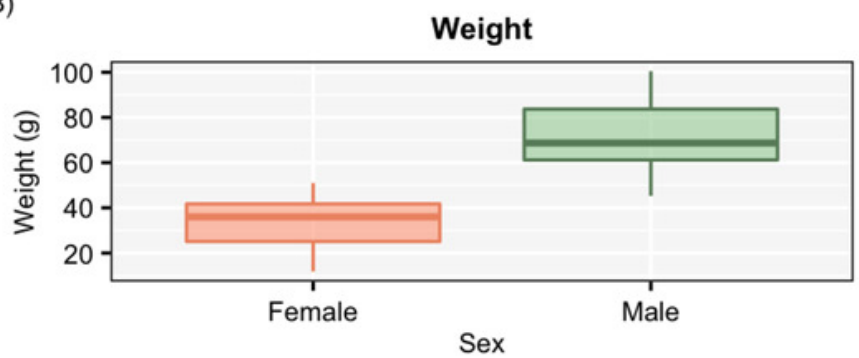

(C)

Number of samples

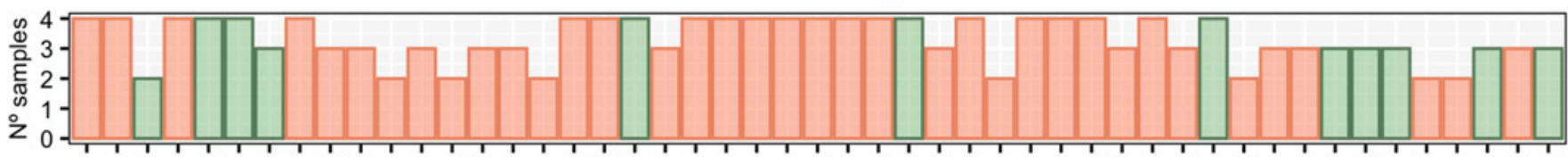

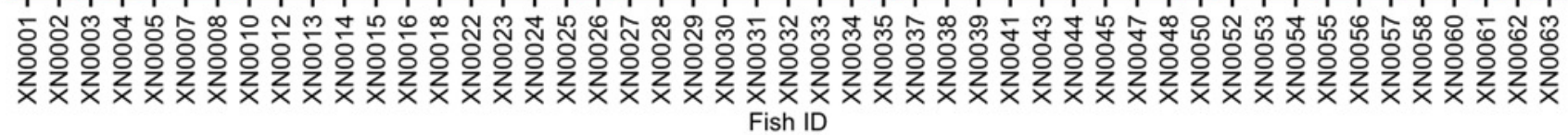

(D)

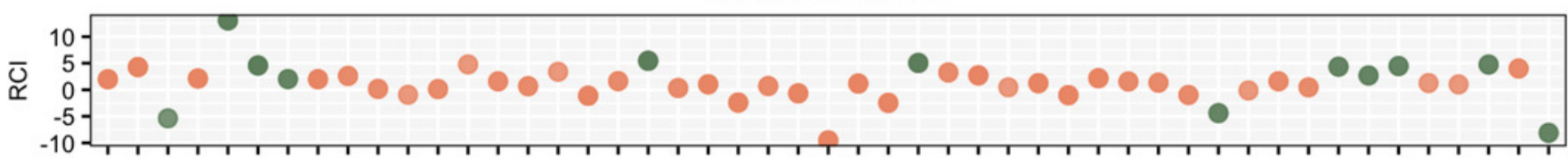

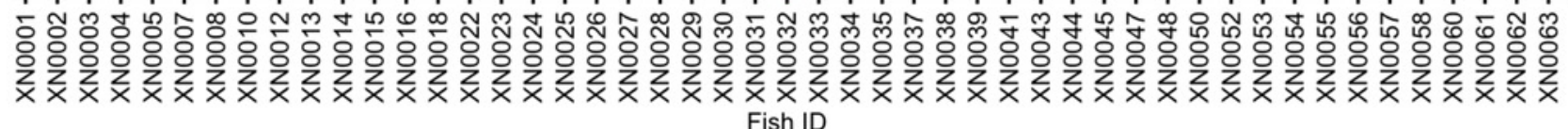


Figure 3

PCA (Principal component analysis)

Graphical representation of the two components (PC1 and $\mathrm{PC} 2$ ) from the principal component analysis (PCA) and the three correlated aggressiveness metrics (number of bites, rams and charges). Males are represented in green and females in orange.

\section{- $F \circ M$}

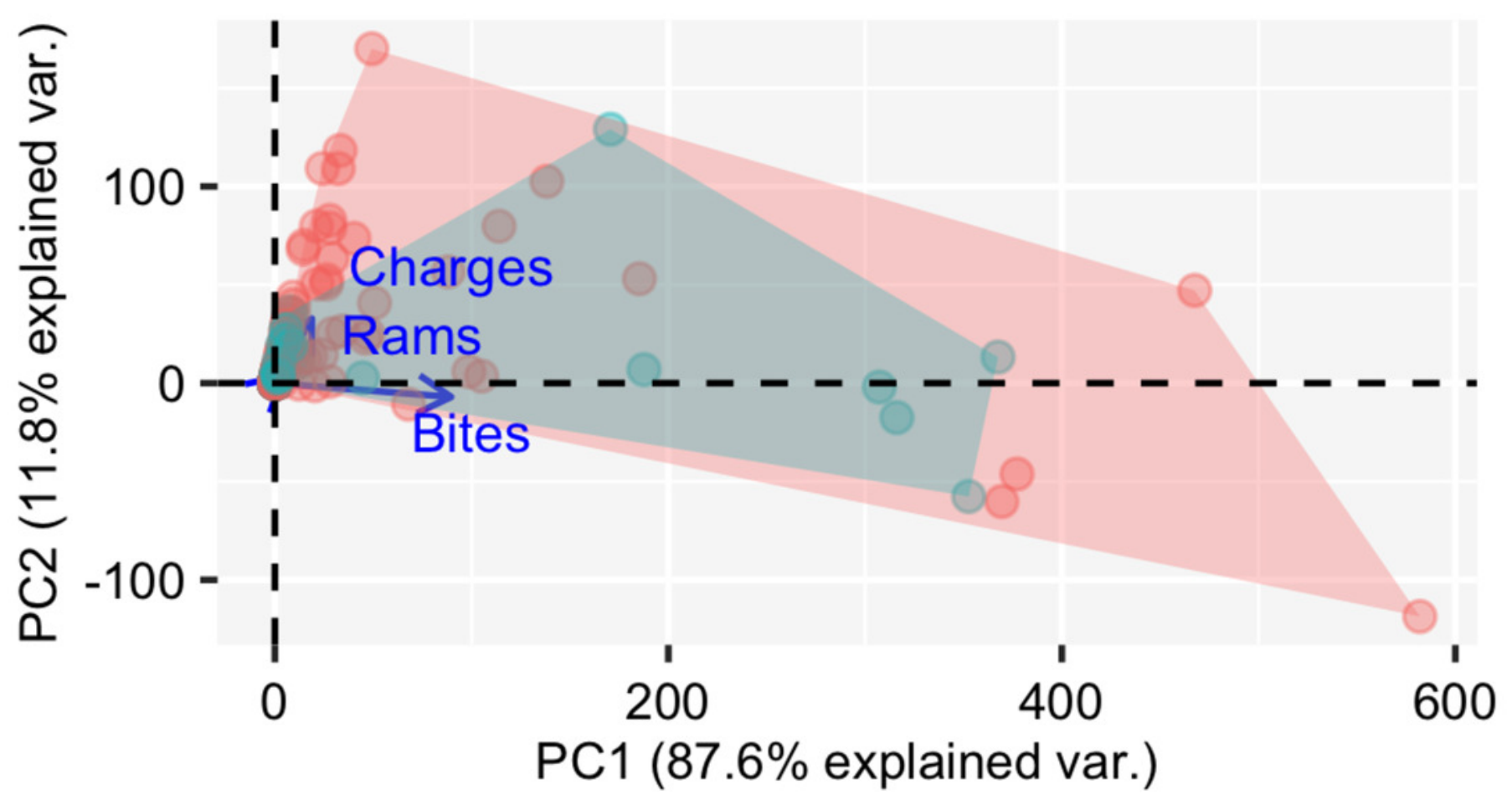


Figure 4

Results for data set

Results of aggressiveness scores obtained from the complete data set (including males and females). (A) Density population plot. (B) Individual's aggressiveness score per each experimental day, where each colour represents an individual. (C) Violin plot representing the individual's variance of aggressiveness scores, where each dot represents the mean aggressiveness score for each individual. Females are represented in orange and males in green.

(A)

(B)
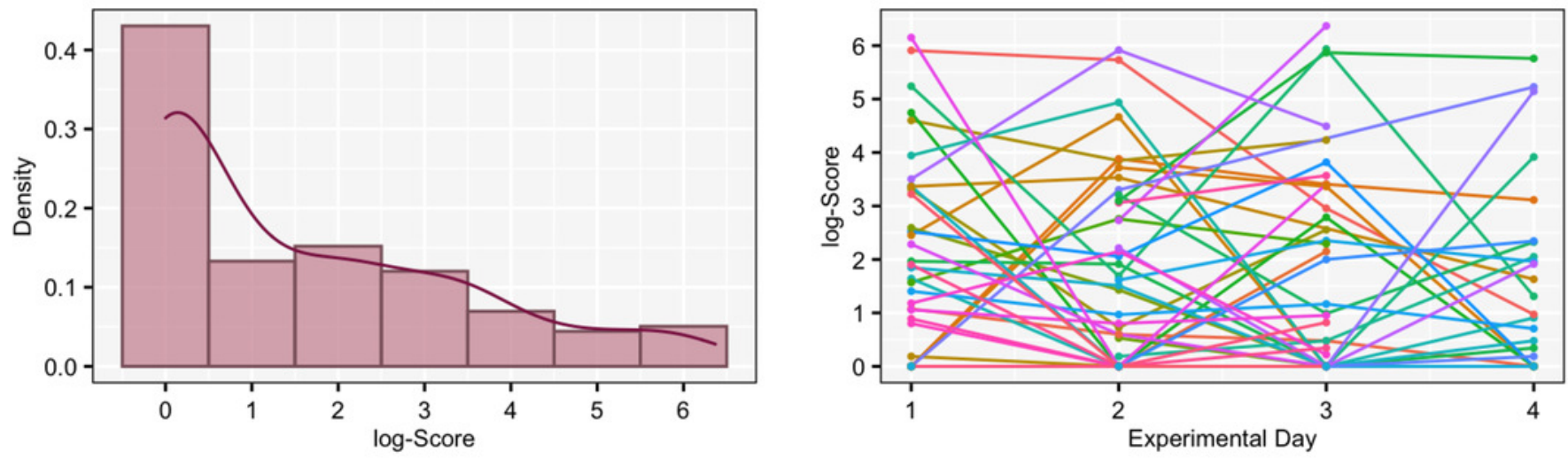

(C)

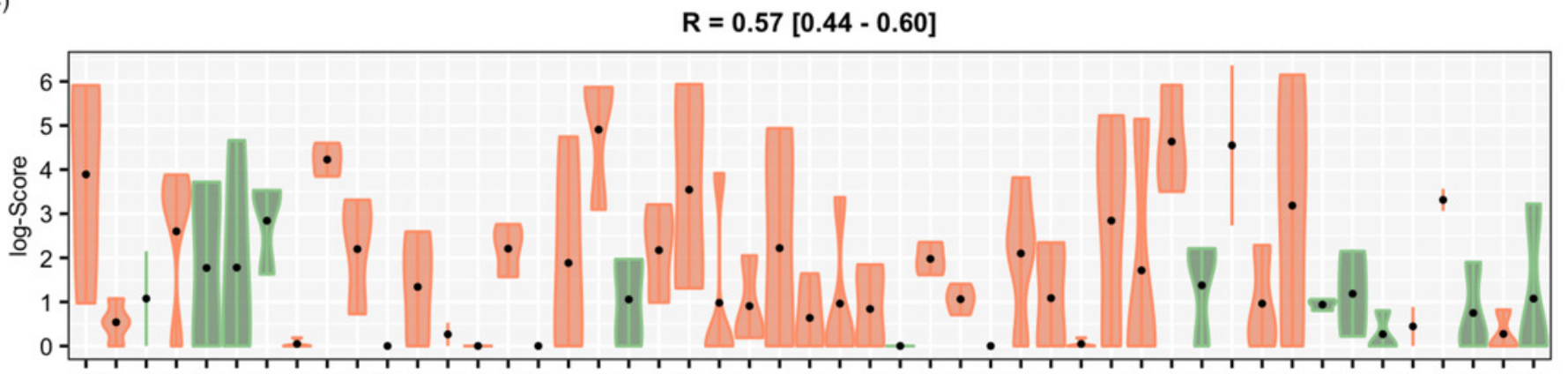

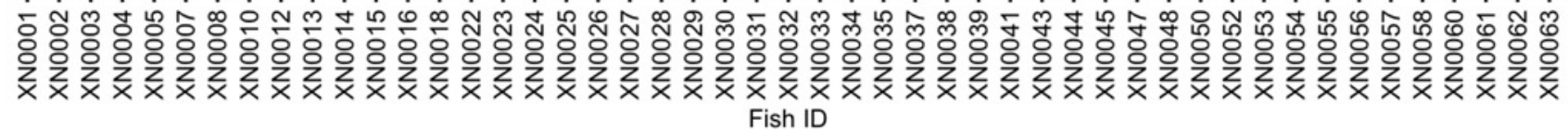


Figure 5

Results for females-only data set

Results of aggressiveness scores obtained from the female-only data set. (A) Density population plot. (B) Individual's aggressiveness score per each experimental day, where each colour represents an individual. (C) Violin plot representing the individual's variance of aggressiveness scores, where each dot represents the individual's mean.

(A)

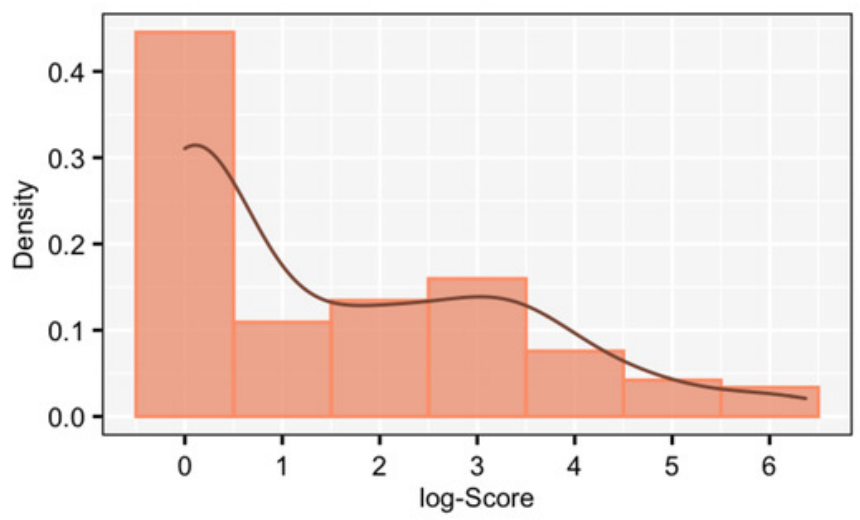

(B)

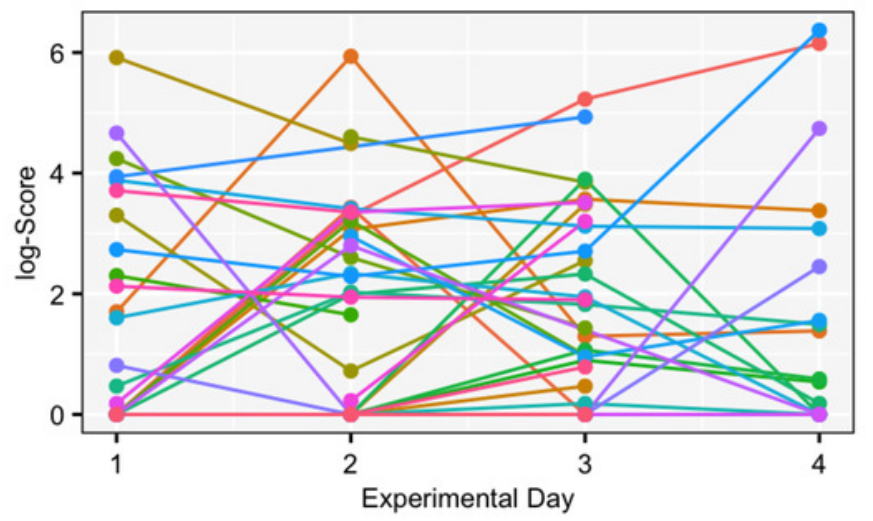

(C)

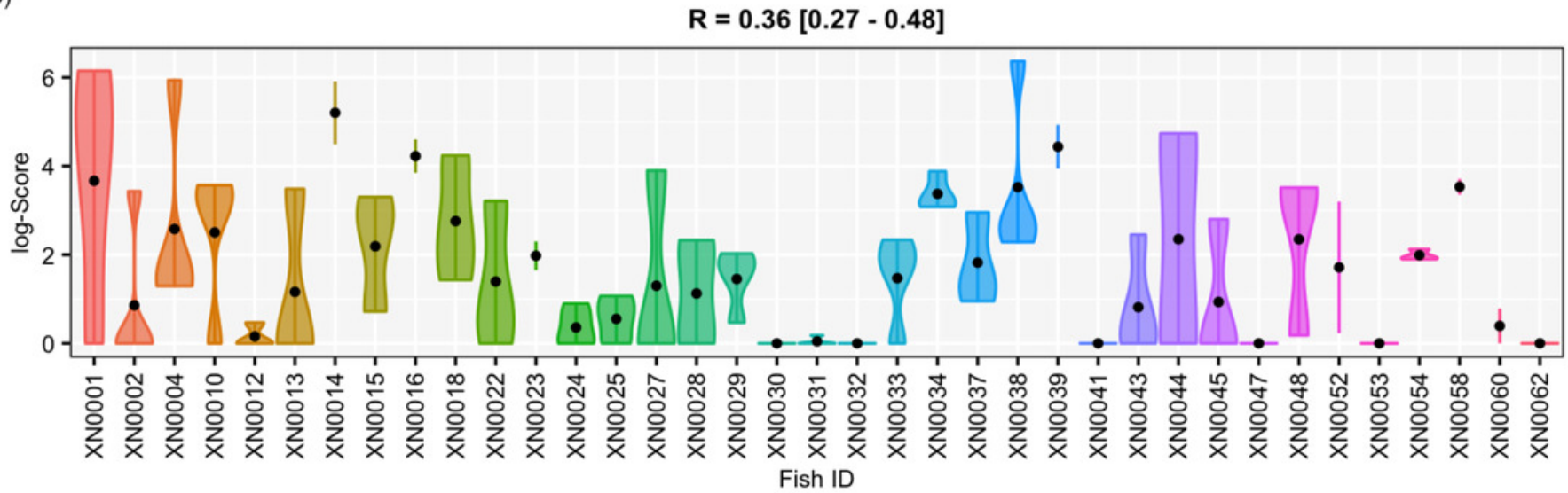




\section{Table $\mathbf{1}$ (on next page)}

Results of the GLMM for the complete data set

Results of the GLMM for the complete data set (including males and females). Environmental covariates with their lower and upper $\mathrm{BCl}(\mathrm{I}-\mathrm{BCl}$ and $\mathrm{u}-\mathrm{BCl}$, respectively) are shown. The model was fitted by 3 environmental variables: experimental day, body size (related with sex: the males were bigger than the females); and the relative condition index $(\mathrm{RCl})$. None of these variables have an effect on aggressiveness. The table also shows the adjusted- $\mathrm{R}$ score, statistically significant as evidenced by the values of DIC and DICC, the between- (Vind0) and within-individuals $(\mathrm{Ve} 0)$ variances and $\mathrm{p}$-values. 


\begin{tabular}{|l|c|c|c|c|}
\hline & Mean & l-BCI & u-BCI & p-value \\
\hline Intercept & 1.68 & 1.27 & 2.12 & $<0.001^{*}$ \\
\hline Experimental day & 0.17 & -0.03 & 0.37 & 0.09 \\
\hline Body Size & 0.12 & -0.32 & 0.59 & 0.59 \\
\hline RCI & -0.08 & -0.50 & 0.39 & 0.73 \\
\hline $\mathrm{V}_{\text {ind0 }}$ & 1.90 & 1.08 & 3.02 & \\
\hline $\mathrm{V}_{\mathrm{e} 0}$ & 1.54 & 1.18 & 1.95 & \\
\hline Adjusted- $R$ & 0.57 & 0.44 & 0.60 & \\
\hline $\mathrm{DIC}=558.22(\mathrm{DICc}=641.32)$ & & & \\
\hline
\end{tabular}

1 


\section{Table 2 (on next page)}

Results of the GLMM from the female-only data set

Results of the GLMM for the females-only data set. Environmental covariates with their lower and upper $\mathrm{BCl}(\mathrm{I}-\mathrm{BCl}$ and $\mathrm{u}-\mathrm{BCl}$, respectively) are shown. The model was fitted by 3 environmental variables: experimental day, body size and the relative condition index $(\mathrm{RCl})$. None of these variables have an effect on aggressiveness behaviour as in the complete data set. The table also shows the adjusted-R score, statistically significant as evidenced by the values of DIC and DICC, the between- (Vind0) and within-individuals (Ve0) variances and $p$ values. 


\begin{tabular}{|l|c|c|c|c|}
\hline & Mean & \multicolumn{1}{c}{ l-BCI } & u-BCI & p-value \\
\hline Intercept & 1.65 & 1.20 & 2.13 & $<0.001^{*}$ \\
\hline Experimental day & 0.14 & -0.11 & 0.40 & 0.31 \\
\hline Body size & 0.10 & -0.37 & 0.56 & 0.68 \\
\hline RCI & 0.02 & -0.39 & 0.45 & 0.90 \\
\hline $\mathrm{V}_{\text {ind0 }}$ & 1.42 & 0.45 & 2.66 & \\
\hline $\mathrm{V}_{\mathrm{e} 0}$ & 1.75 & 1.37 & 2.61 & \\
\hline Adjusted-R & 0.36 & 0.27 & 0.48 & \\
\hline $\mathrm{DIC}=481.33$ (DICc $=446.62)$ & & & \\
\hline
\end{tabular}

1 